\title{
A Decomposition of Differences in Concentration Indices: With an Application to Socio-economic Inequality in Over-nutrition in India
}

Toshiaki Aizawa ( $\boldsymbol{\nabla}$ toshiaki.aizawa3818@gmail.com )

Transition of the BMI Distribution in India

Research

Keywords: Socio-economic inequality, Concentration index, Decomposition, Re-weighting, India

Posted Date: November 19th, 2020

DOI: https://doi.org/10.21203/rs.3.rs-110429/v1

License: (c) (1) This work is licensed under a Creative Commons Attribution 4.0 International License.

Read Full License 


\section{Abstract}

Background: This paper proposes a new semi-parametric method to decompose the differences between two concentration indices. Statistical property of copulas is used to model dependence between health and socioeconomic status. The proposed methods are applied to differences in socio-economic inequality in over-nutrition between rural and urban areas in India, along with existing decomposition

Methods: Taking advantage of the statistical property of copulas, we first decompose the observed differences into the part which is due to the differences in the dependence structures (the dependence effect) and the other part due to the differences in the marginal distributions of health (the health effect). Next, we decompose both effects further into parts explained by differences in the covariates in the model and the part that cannot be explained by them.

Results: The results show that the difference in the proportion of Hindus and the proportion of households that use safe cooking fuel contribute the most to the observed differences.

Conclusions: Comparison among different approaches suggests that the identifying assumptions play substantial roles in the decomposition analysis.

\section{Full Text}

This preprint is available for download as a PDF.

\section{Figures}




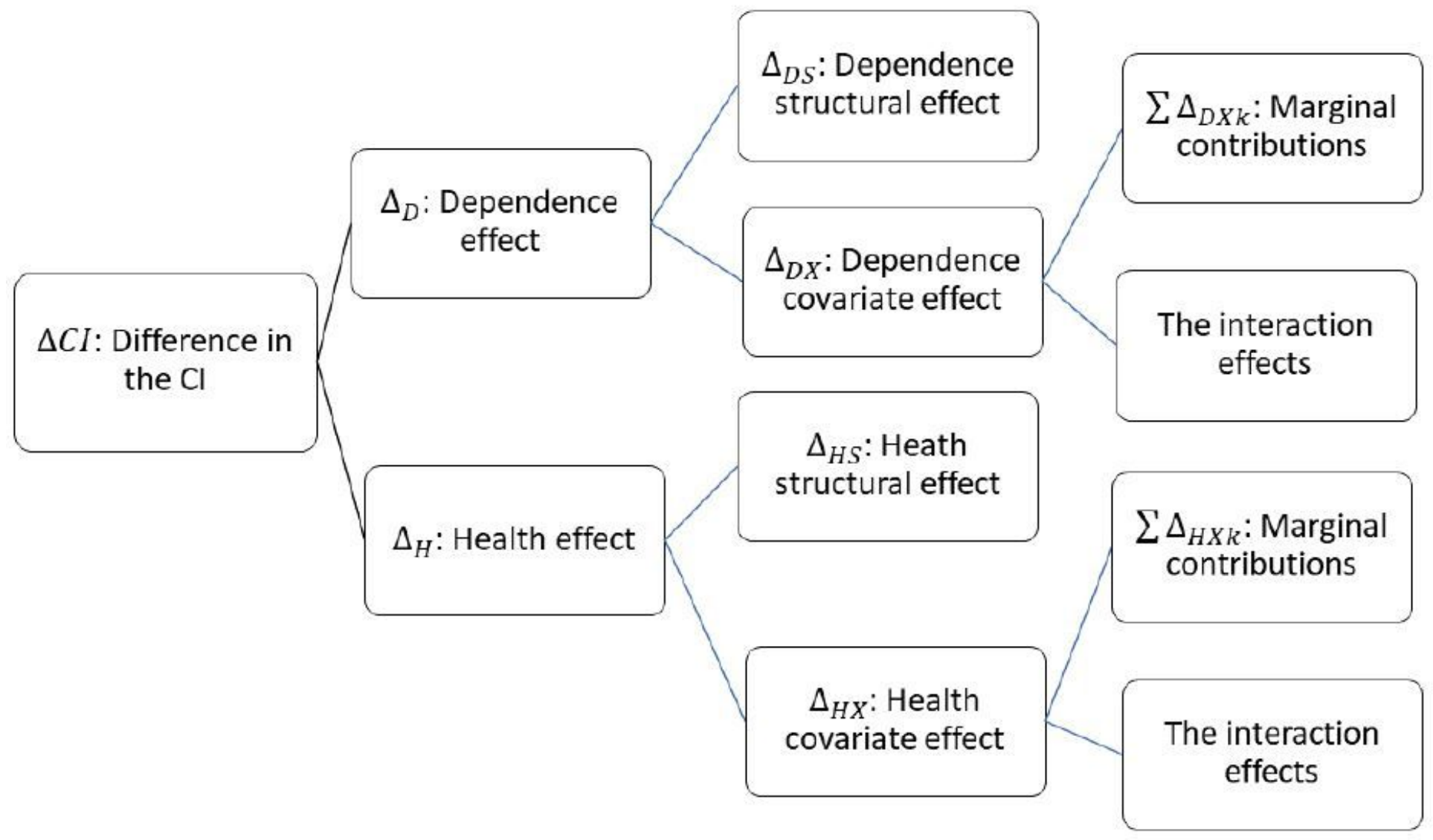

Figure 1

Overview of the $\mathrm{Cl}$ decomposition 


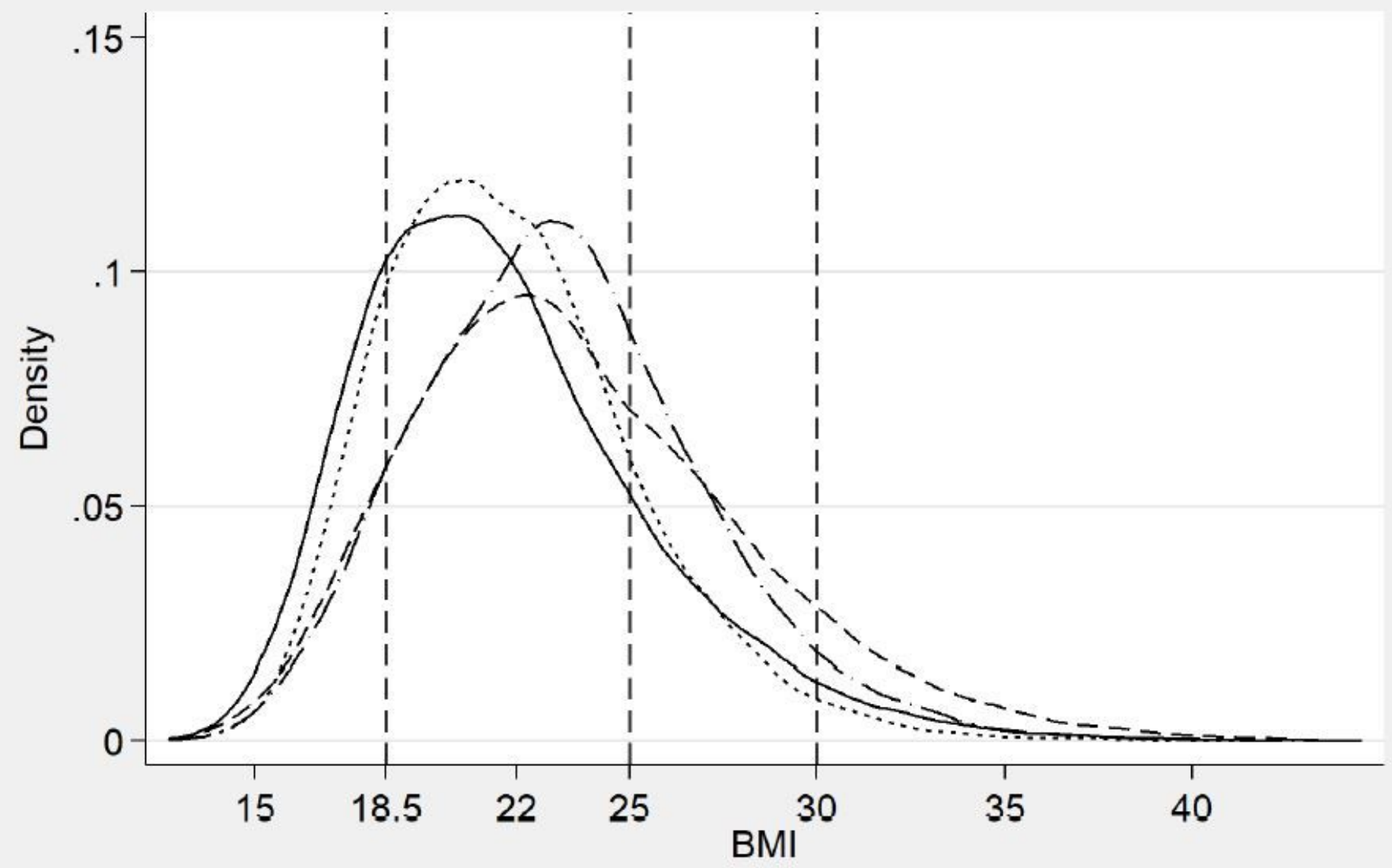

Figure 2

BMI densities 

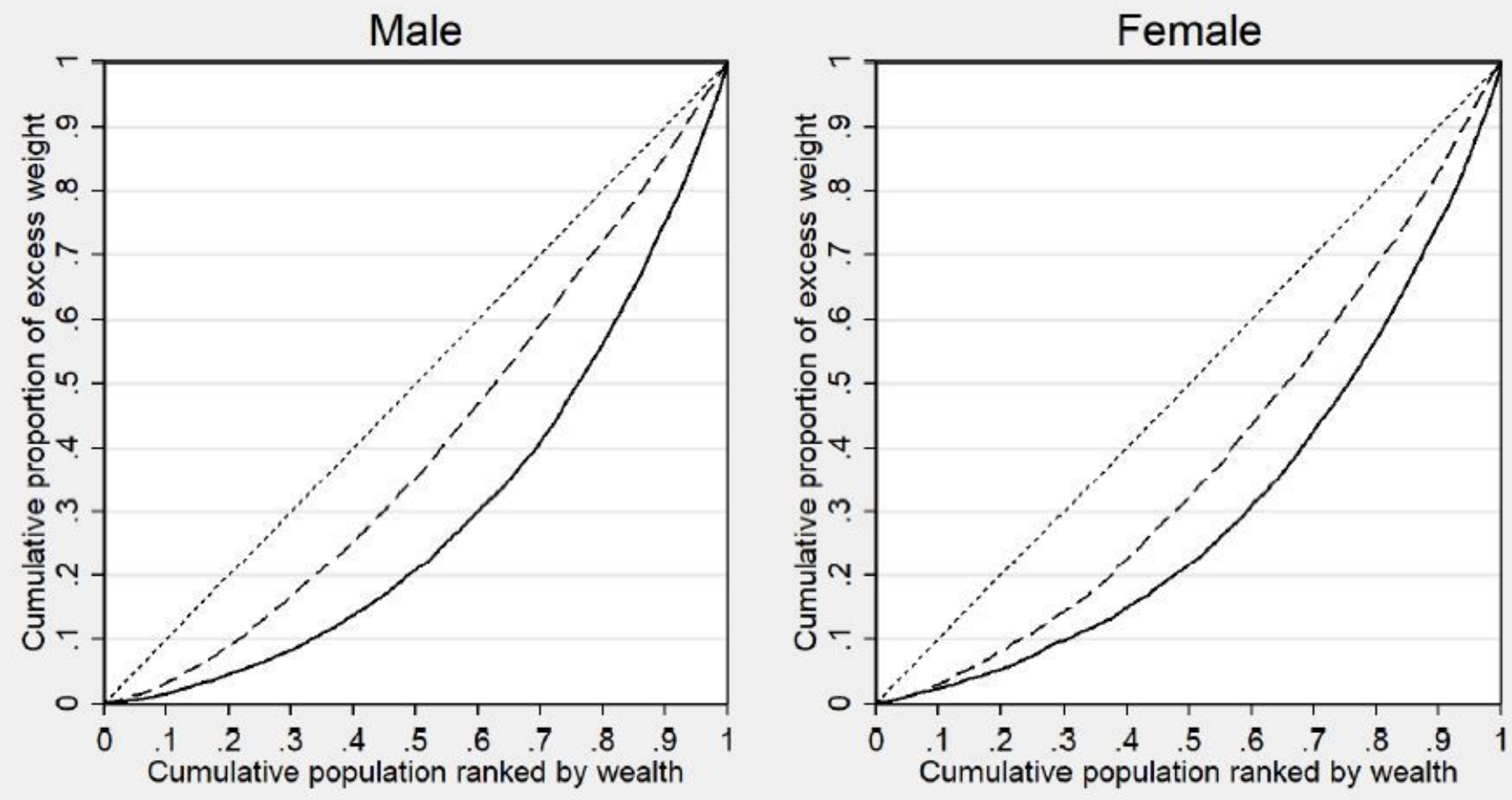

Rural ----- Urban Line of perfect equality

Figure 3

Excess weight concentration curves 